\title{
Collaborative Content Construction: A Pedagogical Architecture to support distance education
}

\section{David Brito Ramos ${ }^{1,2}$, Ilmara Monteverde Martins Ramos ${ }^{2}$, Alberto Castro ${ }^{1}$, Elaine Harada Teixeira de Oliveira ${ }^{1}$}

${ }^{1}$ Institute of Computing - Federal University of Amazonas (UFAM) - Manaus - AM Brazil

${ }^{2}$ Federal Institute of Education, Science, and Technology of Amazonas (IFAM) Campus Parintins - Parintins - AM - Brazil.

\{david.brito, ilmara.martins\} eifam.edu.br,

\{alberto, elaine\} @icomp.ufam.edu.br

\begin{abstract}
This work presents a proposal of pedagogical architecture called Collaborative Content Construction, which relies on the collective construction of knowledge through relational pedagogy, supported by the genetic epistemology of Jean Piaget. Pedagogical architectures represent a way of contributing to innovation in the use of technological support in learning. This proposal includes a methodology that simultaneously builds, collectively and interactively, knowledge, and also leads to the development of materials that benefit participants even after the end of the activity, because in addition to learning in the process, we expect resulting learning material to be more attractive to the students since it would be developed by their peers.
\end{abstract}

\section{Introduction}

To reformulate the practices of the teaching-learning process, teachers seek to use methodologies that can provide the best results in learning. Currently, the idea of teaching is not limited to just helping to assimilate content but to make students reflect critically on what they learn and envision their participation in solving real problems. The training of students starts to increasingly value proactivity, the ability to work in groups, and to solve problems. In this context, student-centered methodologies have been highlighted.

Composing virtual environments with the simple application of traditional classroom methods in the context of online education can be considered inadequate. It is necessary to add the technology factor when designing the method, bringing true conformity with the reality of education today. From this need, the Pedagogical Architectures (PAs) arise, in which the learning strategy includes technological support as part of it and not just a separate/external support. PAs are like learning structures that integrate pedagogical approach, technologies, and time and space conception [Carvalho, Nevado, Menezes 2005].

In this work, a proposal for a PA that uses technologies to support the relationship between participating students is presented, as well as to maintain a historical and sequential record of the actions taken to facilitate the assessment of the steps performed.

The objective of this PA is the cooperative production of content using the agenda, as the journalism style. Under the mastery of a theme aligned with the teacher's learning 
purposes, groups of students select sub-themes, these can be pre-selected by the teacher, if necessary. Each group must carry out previous research on the sub-themes of other groups and, for each of them, suggest an agenda, from which they want more details, which must be related to the sub-theme. Then the group that received the agenda, analyzes them, and checks if they proceed. Then, the group must produce content to be presented that incorporates, but is not restricted to, the suggested agenda. The other groups evaluate the production of colleagues, according to the agenda they suggested. The teacher specifies deadlines for each phase, follows step by step until the end of the activity. The PA was developed thinking about the need to join pre-determined themes/contents (by the school system/curriculum/teacher), to the independence in the choice of research topics made possible by PAs such as "Learning Projects (LP)".

The rest of the article follows this structure: Section 2 presents the related work, Section 3 presents the vision of the proposed PA, which is detailed in Section 4. Then, a practical example is presented as validation in Section 5, and finally, Section 6 presents the final considerations.

\section{Related Work}

The proposal by [Borges and Menezes 2018] presented a PA called APAME that uses educational makerspaces for the construction of knowledge. APAME aims to produce physical artifacts from the development of skills and competencies acquired in the areas of design, computing, and engineering.

The research of [Soares and Castro 2018] consists of a PA to represent digital learning portfolios that are used for the systematic recording of impressions and reflections on guiding themes, as well as to determine the collective and individual effort in the formation of knowledge.

[Reinoso et al. 2017] proposed an PA called APMSII (Pedagogical Architecture for assembling an intelligent irrigation system) for the construction of a smart irrigation system. APMSII aims to build knowledge through skills and competencies that students will acquire when building solutions using experimental robotics in real-world cases.

The work of [Marcon et al. 2012] reports the use of Facebook as part of a PA, where an online group was created for discussions related to the content worked on by the participants. The study concluded that the analyzed social network can be a PA since it is intensively mediated by the teacher.

[Biancardi et al. 2020] presented a PA for cooperative knowledge building. In this PA teacher selects a set of materials called Study Objects (SO). Students selects one SO and make a product, for example, a report about it. After peer review, students make groups considering the $\mathrm{SO}$ in common. The groups make a new product. Teacher analyzes the new productions and give feedback for products and students' participation.

Given the above, it appears that several PAs contribute to the knowledge construction and that it is important to think about aligning pedagogical planning with technologies. This research presents a PA entitled Collaborative Content Construction, which is based on the collective construction of knowledge through relational pedagogy, supported by Piaget's genetic epistemology [Becker 2012]. Following are more details on the proposed PA. 


\section{The pedagogical architecture Collaborative Content Construction}

The proposed PA is based on constructivist principles, where there is no greater weight for the subject or object, but a balance between them. Thus, the principles of relational methodology centered on the subject's action/reflection on the object are followed.

In summary, the PA proposes the following dynamic, as shown in Figure 1. The teacher defines a general study theme, under which students will work. Groups of 3 to 5 students are created. Then, each group selects a sub-theme with which they want to work. Once the sub-themes are established, each group must carry out previous research on the sub-themes of the other groups and, for each of them, suggest an agenda, of which they want more details, such as the explanation of a concept or phenomenon, for example, that must be related to the sub-theme.

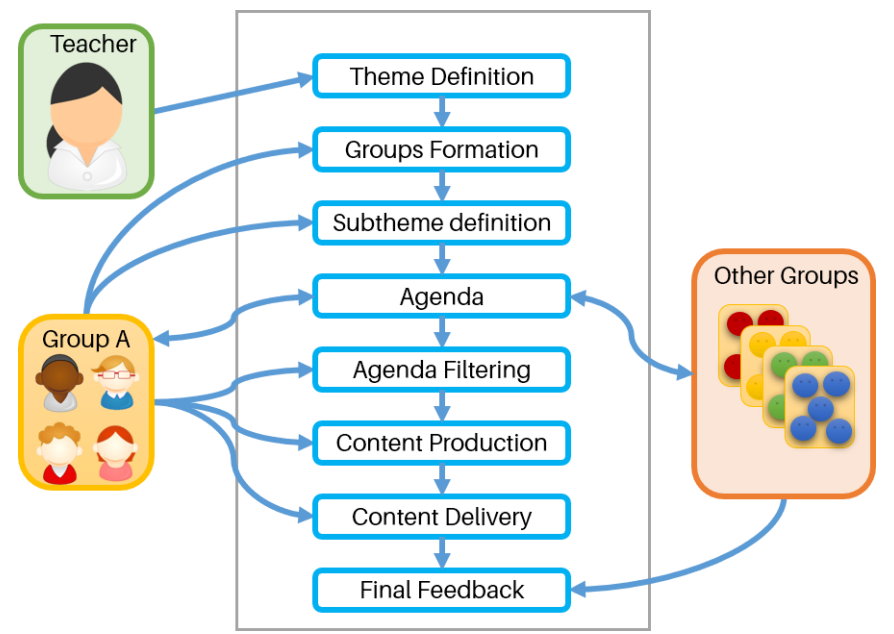

Figure 1. PA Collaborative Content Construction Structure.

Then the group that received the agenda, analyzes them, and checks if they proceed, justifying if they reject any agenda item. Then, the group must produce content to be presented that incorporates, but is not restricted to, the approved agenda. Preferably in a fluid way and presenting examples closer to their realities, if applicable. The teacher decides what the presentation format will be, it can be, for example, audiovisual or an article. The other groups evaluate the production of colleagues, as a whole and according to the agenda they suggested. The teacher evaluates in general the coherence and adherence of what was presented concerning the theme of the work. The teacher can also specify deadlines for each stage of the PA as well as monitor/evaluate students in each one. At the end of the activity, the teacher discloses the notes and the final considerations.

\section{Elements of Collaborative Content Construction}

\subsection{Knowledge domain}

The domain of "Collaborative Content Construction" is not limited to a certain area of knowledge, but given its interaction proposal, this AP requires attention when choosing the umbrella theme, it should consider the size of the class, if the theme is limited it will be difficult to choose subthemes, if it is too broad, it may happen that the work of the groups does not become complementary. If this is the case, ideally, the teacher should launch some key subthemes for the choice of groups. 
The proposed PA is strongly based on research, reading, interpretation, and writing actions. The teacher must pay attention to the choice of the theme so that its subthemes are not hierarchical to the point of requiring more work from one group and less from another. There should be always a necessary balance of effort between the teams.

\subsection{Educational objectives}

Following the constructivist principles, this PA aims to support the construction of content interactively and collaboratively. Not only is the student's participation important, but his/her opinion is essential. At the stage where he/she can suggest agenda items, the PA allows that, even in the face of issues, even if already well established, he/she has an opinion, and that opinion will be heard and will be part of the final product. If there are no agenda suggestions, the process does not proceed. This reinforces the importance of cooperative attitudes in the learning process. PA allows you to learn during the content construction process and share what you have learned with other colleagues at the end.

\subsection{Previous knowledge}

In the proposed PA, prior knowledge is necessary mainly in two moments: sub-theme selection and agenda suggestion. First, Students are the generators of the material itself, and when choosing the sub-theme in which they will work together they will also use their prior knowledge on the subject. Then, when suggesting an agenda, they analyze what they knows and what they would like to know in greater depth, helping other teams to compose materials that best correspond to the expectations of their audience, which are the students themselves.

\subsection{Interactionist-problematizing dynamics}

Participants work in groups of 3 to 5 individuals. The sub-theme selection can occur in two ways: 1) previously, the teacher selects sub-themes, and the teams are allowed only to choose among them; 2) each group chooses a sub-theme of work adhering to the main theme. In the second case, the teacher must be careful so that the sub-themes are not contained in each other. That is, a subtopic A cannot be contained in subtopic B, nor the opposite, but there can be partial intersections. For both cases, the teacher will specify a time for each group to exchange ideas and choose their subtopic better.

After choosing the sub-themes, students will check the sub-themes of the other teams and carry out individual research on them. At this point, each team member must suggest an agenda item, such that the number of different agenda items must be equal to the number of team members. Communication within the team is paramount so that there are no repeated agendas. Example: a team with 5 members should suggest 5 different agenda items for each group. This is an individual stage of the PA.

After all the teams have finalized the agenda suggestion, each team must carry out a process to filter its agenda. The agenda items that do not fit the sub-theme should be rejected and justified as to why. The repeated agenda item must also be refused. Communication within the team is paramount so that there are no repeated agenda items.

The next step is to generate the learning content. For this, the group considers its sub-theme, research, and suggestions from the agenda. The entire agenda must be 
included in the generated content. It is up to the teacher to decide the format in which the final content will be provided, for example, an article or an audiovisual product.

\subsection{Distributed pedagogical mediations}

There are no impediments when exchanging ideas between participants from different teams. However, the records of the agenda suggested in the technological support of the PA that will have greater weight in the evaluation of the interaction between groups. The teacher should always check that the sub-themes are under the umbrella theme, if the subtheme is not aligned, the rest of the process will be compromised. The teacher should also find out, for example, if the sub-theme chosen by the group is not very extensive concerning the time available for the activity. Students can consult the teacher at any time, except in the guideline suggestion phase, which must be carried out individually.

\subsection{Procedural and cooperative assessment of learning}

The teacher can assess whether students cooperate with teams, for example, rejected agenda item may indicate that the student did not perform his/her role correctly. In the final delivery of the content, the teacher can assess whether the team correctly covered the subtopic. This is also a time for each student to check if his/her agenda item suggestion, when accepted, was included in the content or not and if it was answered satisfactorily.

At the end of the AP application, the contribution of all participants will be evaluated. The evaluation considers the final product, the collaboration of the participants through the suggestions made, and the use of the received agenda.

\subsection{Computational Support}

Collaborative work always becomes more complex when one participant depends on another to be able to start his/her contribution. Computational support can be applied both to serve as a repository for the contributions of the teams, as well as to monitor and to delimit the participation of the groups, avoiding possible setbacks and actions that are not allowed. The proposed computational support consists of an online virtual system, where students and teachers are registered. The environment has two profile, student, and teacher, which allow the monitoring and recording of all steps of the PA.

The teacher profile has the following features: registration of the theme and subtheme; group management; assignment of students to groups; assignment/confirmation of sub-themes; viewing agenda suggestions; visualization of the final product and each group's forum; control of start and end dates for each stage of the PA including the deadline for sending the product, and the final feedback of the activity.

In the student module, the functionalities are: registration of the sub-theme; registration of the group, individual registration of agenda, where the student sees only the suggestions given by his/her group (in order not to repeat the suggestion); filtering of the suggestions received, in case of rejection of the agenda, a justification field must be filled; access to the group's forum to exchange ideas; submission of the final product; individual evaluation of the content/final product of the other groups and feedback from the teacher. 


\section{Validation with a practical example}

We present the computational support called $\mathrm{AC}^{3}$ (Ambiente para a Construção Colaborativa de Conteúdo - Environment for Collaborative Content Construction) that manages the activities of the PA and a practical example of how to use it with a form of validation. The sequence below represents the point of view of a single group, but the same behavior is replicated for any group in the PA. Figure 2 presents a partial view of the tool applied to a computing class, in the discipline of Artificial Intelligence (AI). To facilitate understanding, only two groups with three members each will be considered. The groups will deliver an audiovisual presentation at the end of the PA.

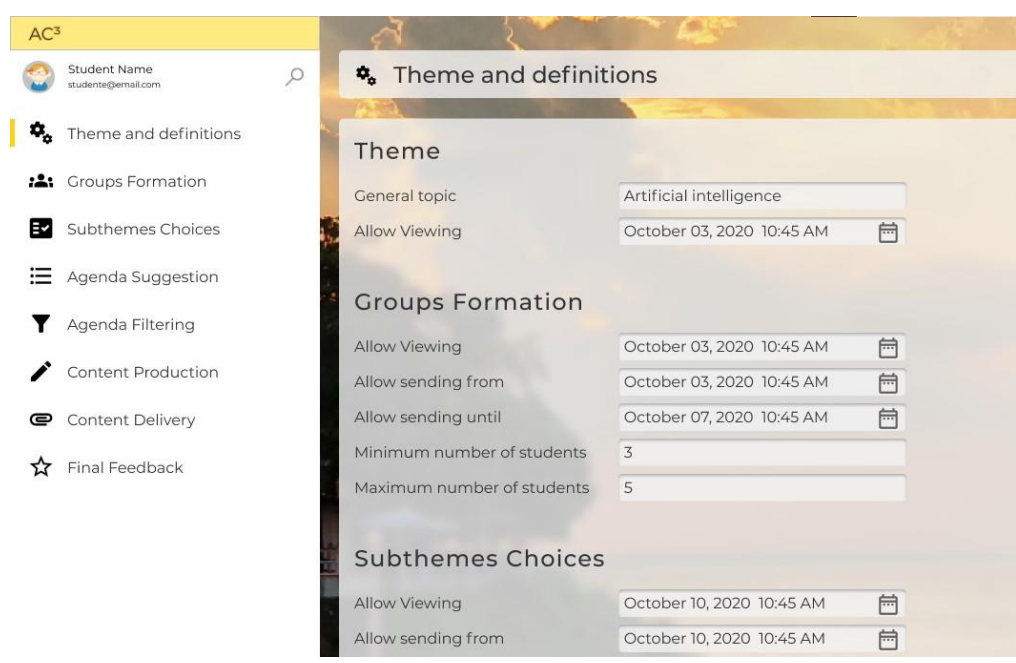

Figure 2. Partial view of $A C^{3}$ showing general definitions.

As shown in Figure 2, in 'Theme and definitions' the teacher launched AI research as a general theme. Still, the same figure shows the delimitation of the deadlines for each stage and the limits, minimum and maximum, of participants per group. Then, in the 'Groups Formation', students make groups and inform each other who will be the representative of the group. Figure 3 shows the visualization after the formation of groups A and B, with their respective representatives, Student 3, and Student 2.

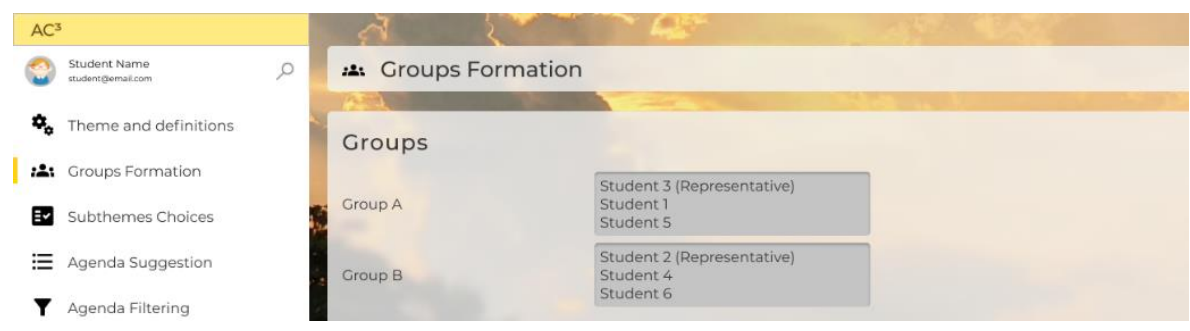

Figure 3. View of the groups formed.

In the subtopic selection phase, group A chose Robotics, while group B chose Computer Vision. The representative is responsible for registering the group theme in the tool. As shown in Figure 4, the teacher receives the subthemes and evaluates whether he approves or not, for example, both were approved. Once the deadline for choosing the sub-theme has ended, the 'Suggestion of agenda' will be enabled. Figure 5 presents the option where a student in group B can send an agenda item to the group A. This phase is individual. As each student sends his/her suggestion, therefore, each group received an agenda with three items. Group A received as agenda suggestions: use of Lego, main 
robotics competitions, industrial use of robotics. Group B, on the other hand, received as agenda: detection of animals, assistance to blind people, weather forecast.

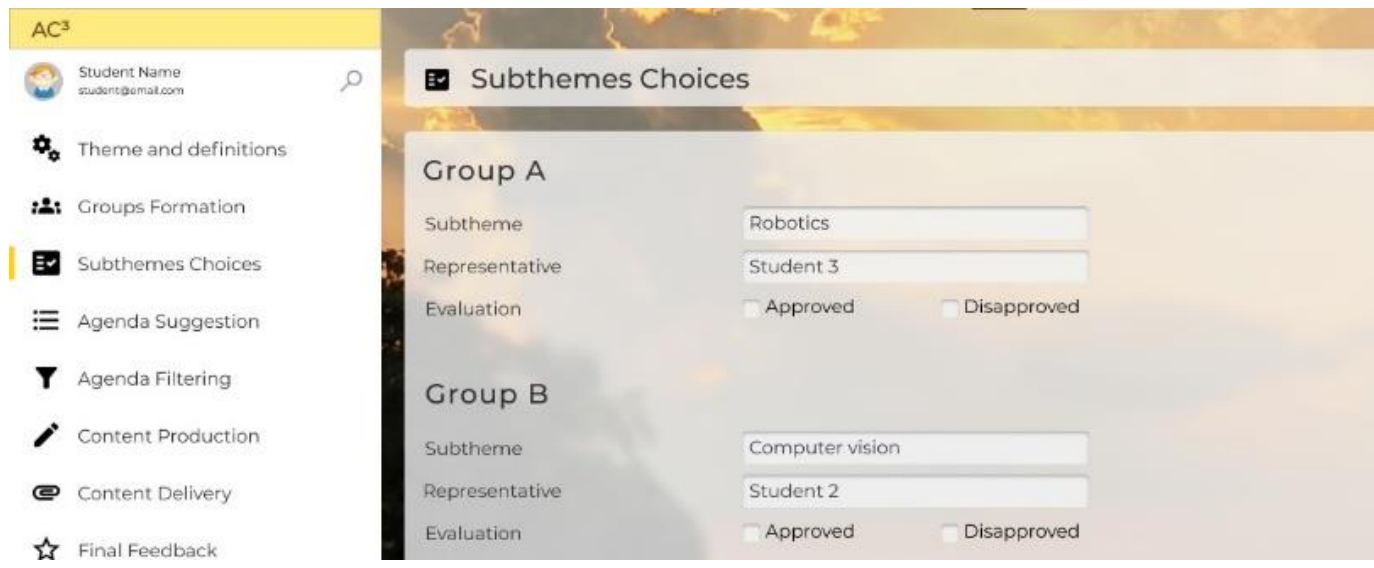

Figure 4. Subthemes approval (teacher options).

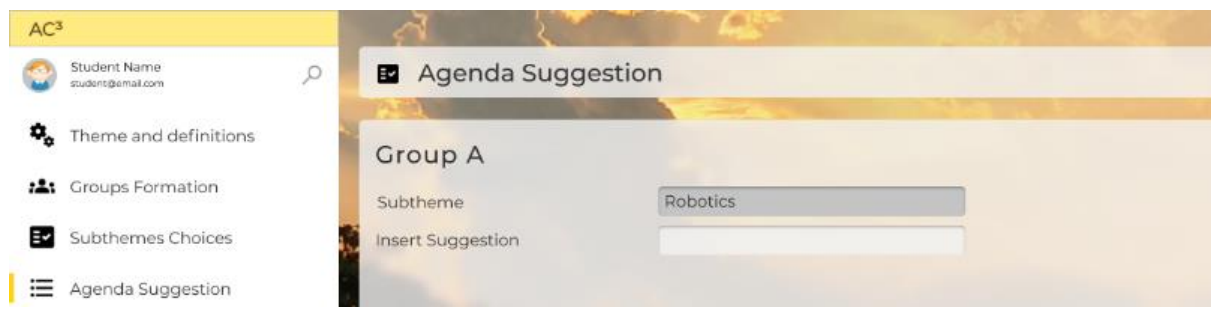

Figure 5. The agenda suggestion.

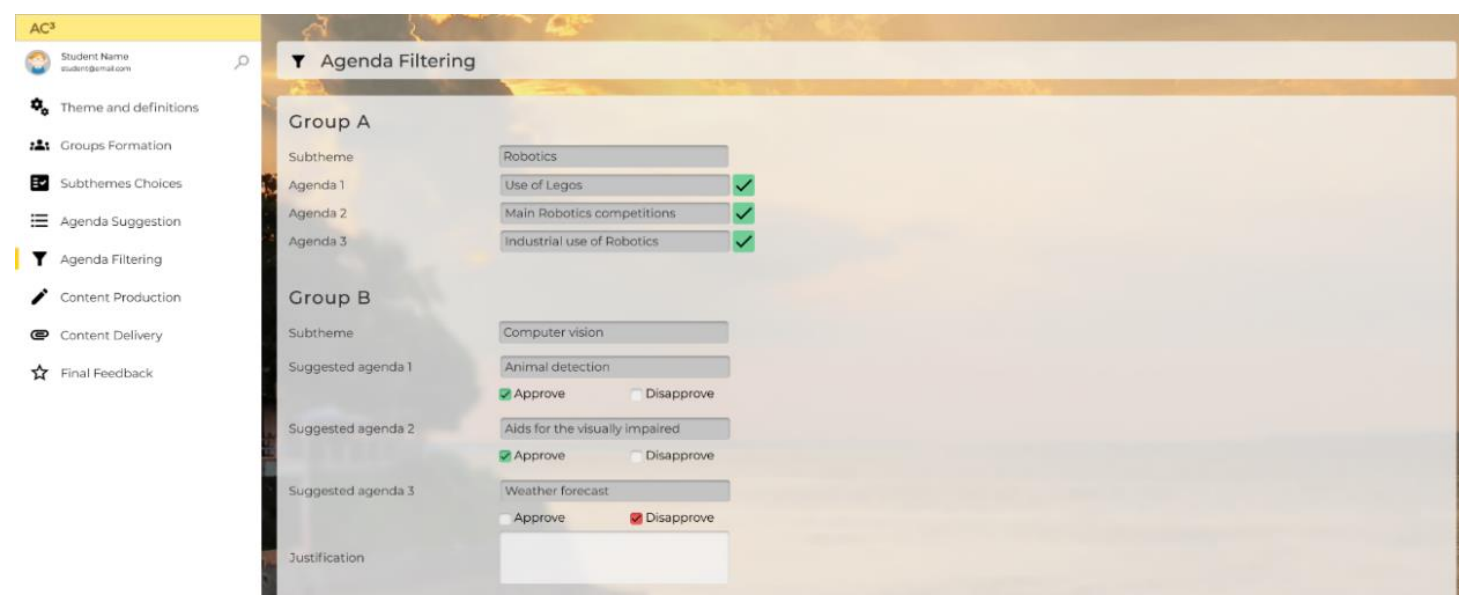

Figure 6. Agenda filtering.

Then, students access the option 'Agenda Filtering', as seen in Figure 6. Group A accepted all suggestions. Group B, on the other hand, rejected the 'weather forecast' agenda justifying that it is more focused on data mining. In the tool, the teacher can see which student suggested the agenda item that was refused. Groups can view the agendas of other groups, but they can only approve or disapprove their agendas. After the filtering of the agenda is complete, the content elaboration phase begins. The groups, in possession of the agenda, begin the work of developing the final product and can interact in the option 'Content Development'. In the end, the representative of each group sends the file containing the product created using the 'Content Delivery' option. The teacher evaluates all content presented, while students evaluate how their suggested agenda was presented. 
The assessment of students must be carried out in the system. The teacher will later post the notes that will be visible in the 'Final Feedback' option.

\section{Final considerations}

This work presented a PA proposal entitled "Collaborative Content Construction", based on relational pedagogy. In the proposed PA, students are led to act collaboratively and, at the same time, to have their opinion as an essential key to the process of product creation and evaluation. So, they can also understand how they are assessed and what criteria were used. Students are expected to appreciate the final product, as it is created by themselves. The next steps in this investigation include a case study in a real use situation where, in the end, students will also be invited to evaluate the various stages of PA, identifying possibilities for improvement. As for technological support, it will be possible to identify adjustments to existing resources, for example, frequency of alerts to participating students whenever a stage approaches the end, in addition to the adequacy of other features.

\section{Acknowledgment}

This research was supported by the Foundation for Research Support of the State of Amazonas (FAPEAM) [PROINT/AM Program, 003/2018]; the Coordination for the Improvement of Higher Education Personnel - Brazil (CAPES) - Finance Code 001; and the Federal Institute of Education, Science, and Technology of Amazonas (IFAM).

\section{References}

Becker, F. (2012). Educação e construção do conhecimento, Penso, 2nd edition. (In Portuguese)

Biancardi, C., Andrade, J. C. S., Santana, S., and Menezes, C. S. (2020). APA2I - Uma Arquitetura Pedagógica Aberta, Adaptativa e Inteligente para Construção Cooperativa de Conhecimento. RENOTE, 18(2), p. 131-140. (In Portuguese)

Borges, K., and Menezes, C. S. (2018). Uma Arquitetura Pedagógica para Aprendizagem baseada na Fabricação Digital. XXIX Simpósio Brasileiro de Informática na Educação (SBIE 2018), p. 457. (In Portuguese)

Carvalho, M. J. S., Nevado, R. A., and Menezes, C. S. (2005). Arquiteturas Pedagógicas para Educação a Distância: Concepções e Suporte Telemático. XVI Simpósio Brasileiro de Informática na Educação (SBIE 2005), p. 351-360. (In Portuguese)

Marcon, K., Machado, J. B., and Carvalho, M. J. S. (2012). Arquiteturas Pedagógicas e Redes Sociais: Uma experiência no Facebook. XXIII Simpósio Brasileiro de Informática Na Educação (SBIE 2012), p. 26-30. (In Portuguese)

Reinoso, L., Amorim, M., Silva, M. S., Hackbart, E. H., and Teixeira, G. (2017). Robótica experimental com uma arquitetura pedagógica para montagem de um sistema de irrigação inteligente. XXVIII Simpósio Brasileiro de Informática na Educação (SBIE 2017), p. 695. (In Portuguese)

Soares, A., and Castro, A. (2018). Uma Arquitetura Pedagógica para Representar Portfólios Digitais de Aprendizagem. XXIX Simpósio Brasileiro de Informática $\mathrm{Na}$ Educação (SBIE 2018), p. 427. (In Portuguese) 